\title{
Хирургичните терапии \\ при съннообусловени нарушения в дишането \\ в исторически аспект
}

\author{
М. Милков" ${ }^{1}$, Цв. Тончев \\ ${ }^{1}$ Специализирана УНГ-клиника "Св. Петка" - Варна \\ гуМБАЛ "Св. Марина" - Варна
}

$\mathrm{B}$

резултат на огромното натрупване на познания за съннообусловените нарушения в дишането (СОНД) през последните 40 години, както и от историята на медицината, ние узнахме, че в лекарските съобщения от миналите векове има пациенти, които много вероятно са страдали от СОНД. Някои от техните симптоми могат вероятно да се сбъркат с хиперплазия или възпаление на увулата, чиято резекция (уволотомия) е била описана още в първите хилядолетия преди Христа от североиндийския лекар Сушрута (Sushruta). Историята за увулотомията, която и днес се практикува в някои североафрикански държави като оръдия от „лечители“, може да бъде запълнена цяла книга.

В немедицинската литература на древните гърци и римляни, научаваме от многобройни източници, че античните хора са правили много точно наблюдения върху това, което днес ние наричаме първично хъркане и обструктивна сънна апнея (ОСА). Дюселдорфският историк по медицина Алберт Есер е събрал много от тези литературни източници през 1941 година в „Зудховския архив за история на медицината и естествените науки“. Тази препоръчителна статия е била преведена на английски и публикувана в „Sleep and Breathing" (2002 г.; 6: 30-39).

От епиграми, писма и речи научаваме, че шумовете от хъркането не са само признак на съня, а също могат да бъдат предизвикани и нарочно. Екзогенните фактори като ексцесивно хранене и пиене, лежане по гръб, падане на долната челюст могат да предизвикат също 
хъркане, както и ендогенните конституционални фактори като възраст (деца, старци), пикничен или плеторичен хабитус с къс и дебел врат. Има илюстрации за акустичните разлики при шумовете от хъркане, които включват от екстремно силно до прекъснато хъркане от дихателни паузи и респираторно подобрение.

Първите указания за хирургическо лечение на хъркащи хора датират от античността. Така например Хипократ (466 - 377 пр.н.е.) описва съвсем точно в ,de morbis Libr. II, Kapt. V“ как един носен полип предизвиква хъркане: „когато полипът излиза (изкача) от носа от средните хрущяли, е като един житен червей, който виси и при издишване е широко навън, а при вдишване се прибира и той предизвиква приглушен глас и хъркане по време на сън“. Хипократ оповестява тогава наред с няколкото консервативни терапевтични модела и пет оперативни метода за отстраняване на носен полип, един от който е бил нарисуван през 1895 г. от Baldewein (изображение 1).

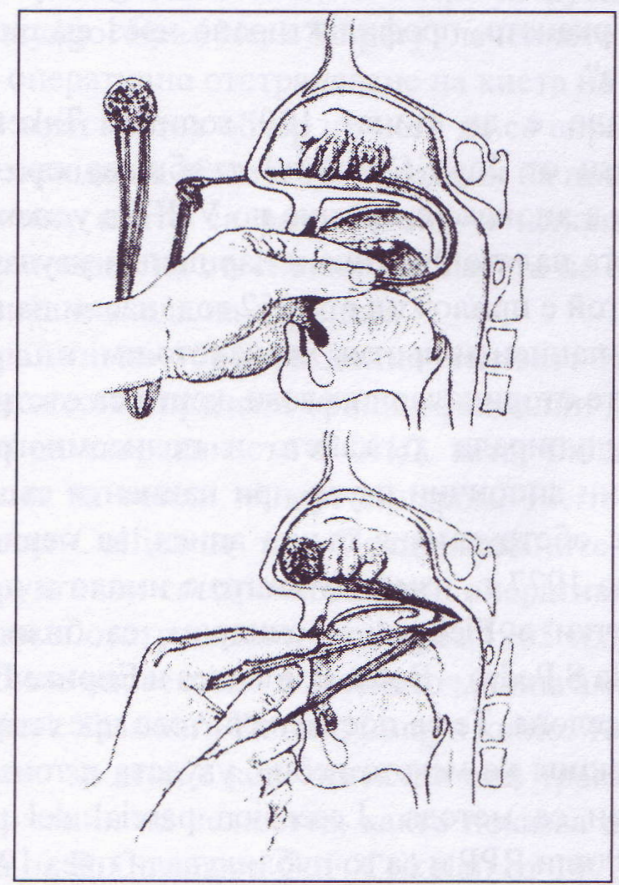

Хипократ (Prognostica XXII) диференцира съвсем ясно кога трябва да се отстрани една увула и кога не: „Опасно е да се изрязва напълно или да се пробожда увулата, когато тя е червена и уголемена... където... се образува това, което ние наричаме „грозд“, тогава това означава, че долният край на увулата е уголемен и ливиден, докато горният е по-тънък, тогава е сигурно да се оперира“.

Най-ранните инструменти за увулотомия са запазени от римско време. Те са били обичайно от бронз, като напр. клещи за изтръгване на увула (Ctaphylagra) от IV век след н.е., които аз открих в
Оксфорд в Ashmolean - музея. Фините зъбчета за захващане са покрити с платина, което говори, че вероятно увулата е била отстранявана чрез теглене по дължина.

Най-ранното изобразяване на увула и небните тонзили се открива при Леонардо да Винчи (1452 - 1519 г.) върху рисунки от 1510 година, който при това описва в своя огледален ръкопис, че увулата е „крайъгълен камък“ за оттичане на капки от секрети, идващи отгоре, и по път на хранопровода отиващи в корема, което е валидно и до днес като наблюдение“.

Амброз Паре (1510 - 1590 г.), баща на хирургията във Франция, споменава през 1564 година в своя раздел за увулата (Dix livres de la shirurgie...), че от нея се предизвиква хъркането: „Sonvent lehrunk de cervean la (luette) fait denfler et elle cause plusieurs accidents".

Когато консервативните мерки не дадат успех, трябва да се катетеризира увулата с игла или в екстремни случаи да се отстрани чрез завързване с шнур (изображение 2).

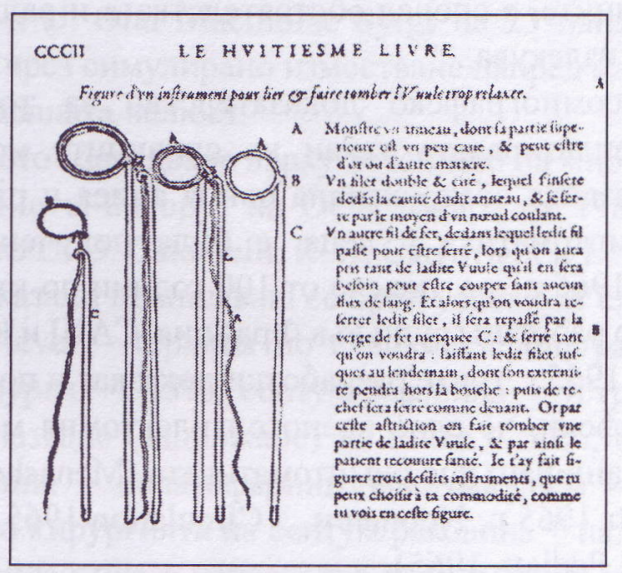

Златните игли, които лекарите на Дионисиус (360305), тиранът на Хераклеа на Черно море и съвременник на Александър Велики, са използвали за да държат господаря си буден, са били навярно първите хирургични инструменти на Античността, които документирано са били използвани за терапия на ОСА. Дионисиус, който от всичко наймного е обичал яденето и пиенето и е живеел само за това, е бил толкова дебел, че накрая е трябвало да го хранят изкуствено. Неговата дневна сънливост и апнея са били прекъсвани от лекарите му чрез следните мерки: те са набождали златни игли през кожата на корема и подкожната мастна тъкан, докато иглите достигнат до болкочувствителните коремни мускули и събудят владетеля. Накрая той се е удушил в собствените си мазнини. Атенеус (Athenaeus) около 200 г. след н.е. е предал сведе- 
ния как си е представил Дионисиус своята смърт: „Аз мечтая за едно нещо за самия себе си - и то изглежда за мен като единствената смърт с щастливо умиране - да лежа по гръб с множеството гънки мазнини, да нямам думи, мъчейки се да дишам, докато се храня и да казвам: „Аз си заминавам с удоволствие

От началото на 80-те години съществуват опити успешно да се намалят проблемите на ОСА при масивно свръхтегло чрез намаляване на стомашно-чревния тракт (Бариатрия) (Charuzi и сътр. Surgery 1985).

Отстраняването на небните тонзили е било описано още от Хипократ. За успешни тонзилотомии при хъркащи деца съобщава д-р Фридрих Бету от Хайлброн през 1858 г. Той е наблюдавал при 3 годишно момче: „... така се появяват вдишвания с хъркане, при което съвсем ясно се вижда, че небното платно заедно с мъжеца не взема участие, защото не се привежда в движение“. И по-нататък той пише: , ...и тъй като хъркането е предизвикано от хипертрофирали сливици, ...хъркането може в такива случаи да се намали чрез ампутация на сливиците, а според обстоятелствата и радикално да се излекува..."

Полисомнографско доказателство за това, че хиперплазиралата тъкан на сливиците може да предизвика обструктивна сънна апнея и рicкwick - симптоматика у деца, е била получено едва през 1965 г., т.е. повече от 100 години по-късно от много работни групи във Франция, САЩ и Канада. През 1965 г. трите разработки доказват и полисамнографски, че една аденотонзилектомия може да отстрани напълно симптоматиката (Menashe и ... S Pediatr 1965 г.; Noonan и ... Circulation 1965 г.; Cox и ...: S Pediatr. 1965).

Едва през 60-те години на последния век са били постигнати за първи път хирургически успехи при терапията на СОНД чрез кардио-респираторните и ЕЕГ - находки, документирани по време на сън.

Това не се основава само на цитираните успехи от аденотонзилектомия при деца с ОСА.

Относно индикациите за трахеотомия като средство срещу хъркането е открита една ранна разработка на Marchall Hall в Lancht 2 от 1848 година. Той препоръчва тя да се извършва при пациенти с епилепсия, тежък алкохолизъм и апоплексия. Дали тя наистина е била извършена, не можем да знаем. Затова важи по принцип, че първа е документираната чрез полисомнография трахеотомия на W. Kuhlo, E. Doll и M. C. Franck в Университета във Фрайбург: „Успешно лечение на Dickwick - синдром чрез постоянна трахеална канюла“ (Deutsche Medizinische Wochenschoift 1969).
Аденотомия: значението на хипериаластичните сливици е било изяснено едва през 19. век. Лекарят от Копенхаген Meyer (1844-1895) е изследвал систематично аденоидите и техните симптоми, особено ролята им при СОНД. В датското списание за практикуващи лекари "Hospitas-Tilende" от 4 ноември 1868 г. той обобщава своя опит под заглавието: „за аденоидните вегетации в областта на носогльтката, симптомите, които предизвикват и как са били лекувани“. Той илюстрира и до днес валидните симптоми: нарушение на слуха, проблеми с Евстахиевата трьба, дишане през устата, нарушения в съня, хъркане, сънлив израз на лицето и умора у децата с аденоиди и позитивните въздействия на аденотомията върху тази симптоматика.

Интервенции върху мекото небце: вероятно отдавна мекото небце е било открито чрез самонаблюдение като причинител на шумове на хъркането, което може да изясни индикациите за практикуваната с хилядолетия традиция за увулатомия. Но едва през 1852 година L. A. Dugas публикува за ,Хъркането, профилактирано чрез ексцизия на увулата“".

Трябвало е да минат 100 години. Takenosuke Ikemotsu от Joga (Япония) съобщава през 1964 година в японско списание по УНГ за успехите на неговата палатопластика и парциална увулатомия, които той е приложил от 1952 год. насам на повече от 100 пациенти против хъркането им.

Първите оториноларинголози, които са отстранили или редуцирали хъркането и полисомнографски доказани апноични паузи при пациенти със синдром на обструктивна сънна апнея, за периода от 1974 до 1977 г., измежду които е имало и няколко пациентки с Pickuick - синдром, са били Pedro Quesada S Pedro - Botet, E. Fuentes и Енрике Перело от Барселона. Те са постигнали това чрез парциална резекция на мекото небце, увулата и тонзилите. Нарекли са метода „Leseccion parcial del paladar blaudo“ или RPP и са го публикували през 1977 г. През 1981 год. Shiro Fujita и сътрудници от Детройт са публикували своята често цитирана разработка за „увуло-палато-фаринго-пластика“, с която са лекували пациентите във всякаква степен на тежест на СОНД. Този оперативен метод ce е разпространил бързо в много страни и е бил модифициран от новите технически възможности, за което тук няма да стане въпрос. В последните 2 десетилетия трябва да признаем, че тази много радикална форма на техниката на Fujita непрекъснато се заменя от по-малко инвазивни, свързани с по-малко усложнения техники за хирургия на мекото небце. 
Носни операции: Освен няколкото източника за операция на носни полипи от Хипократ, няма съобщения за операции във връзка със СОНД. Едва в края на 19. век се появиха разработки (Cline 1892; Wells 1898), които съобщават за подобрена дневна активност след операции на септума. Полисомнографски документираните пациенти със СОНД, чиито симптоми са се редуцирали след операция на септума, датират едва от последната четвърт на 20-ти век и в началото са били откривани (смятани) за казуистика (Simmons/Hill 1974 г; Heimer и сътр. 1893 г., Maurer и сътр. 1893).

Операции на основата на езика и ларинкса: За обструкцията на горните дихателни пътища допринасят или макрогласията, гласоптозата при мандибуларна хиперплазия, или хиперплазия на тонзилите на езика. Ruckett и .... (Plastreconstr Surg 1982 г.) е лекувал усилено гласоптоза при дете със синдром на Keippel - Feil и OCA чрез завързване на част от фасция лата, която фиксира към хипопластичната долна челюст.

През 1981 година Olsen и сътр. са публикували (otolaryngol Head Neck Surgery) лечението на OCA чрез оперативно отстраняване на киста на ларинкса. В този кратък обзор не мога да се спра на другите методи от 80-те и 90-те години на последното столетие, които са разработени и използвани за отстраняване на стеснения в областта на основата на езика и входа на ларинкса.

Операции на горна и долна челюст: Известни са множество вродени кранио-фациални дефекти, които са свързани със СОНД, като: билатерална атрезия на конхи, Аперт-синдром, Pierre-Robins, Treacher-Collins и т.н. Предизвиканите от тях обструктивни синдроми са били оперативно редуцирани и отстранявани още през 1965 год., преди да е било оповестено понятието „сънна амнеза“ от Gaustaut, Tassinari, Duront, Lung и kuhlo. Това важи особено за деца с конгенитални или травматични деформации на челюстта, както показва публикацията на B. Cosman и G. F. Crikelair от 1972 година (Plast reconst Surg).

Те са премахнали нощната обструкция на дихателните пътища при малко дете с мандибуларна хипоплазия и билатерална темпоро-мандибуларна анкилоза, използвайки трахеотомия и последваща пластика по долната челюст. По-късно са затворили трафеостомата и през следващите 6 години не са наблюдавали рецидив на обструкцията.

На 60-тия годишен конгрес на Американската асоциация на оралните и максиларно-фациални (лицево-челюстни) хирурзи в Чикаго през 1978 година S.H. Priest докладва за успешно лечение на OCA чрез изместване на долната челюст напред.
Успоредно с това S. F. Precuch показва как при петгодишно дете са се подобрили симптомите на ОСА след реконструкция на долната челюст и изместването ѝ напред чрез трансплантант от ребро. През 1979 г. Кио и сътр. публикуват за успешно лечение на ОСА чрез изместване напред на долната челюст при трима пациенти, двама от които деца, поставяйки трансплантант от ребро във възходящия клон на долната челюст (Oral Surg Oral Med Oral Path).

R. Wittig и сътрудници от Детройт са осъществили успешно изместване на долната челюст напред при трима пациенти с OCA, при които не е имало здрава захапка (с дефектна захапка) (Sleep Res). Публикувани са някои варианта за изместване напред на брадичката или на долната челюст заедно (Zungebein) с окачването (залавянето) през 1983 г. (Bull Eur Physiopathology Resp.) от екип на Стандфордския университет Christian Guillemina nlt Nelson Powell и Robert Riley, (към) която после се присъедини с подобрение в резултата и Le Fort - I - Osteotomia. Също и групата на P. D. Waite от Бирмингам представи успешното лечение през 1989 г. (J. Oral Macillofac Syrg) на 23 пациенти с OCA чрез симулирано изместване напред на горната и долната челюст.

Първото изследване върху лечението на много нива (multi-level-therapy) на ОСА датира от 1985 г. от Чикаго D. D. Caldarelli, R. D. Cartwright и L. K. Lilie са доказали повишаващ се брой успехи от следната multi-level - терапия по стъпки: Septum/раковина - хирургия - $35 \%$; септум/раковина + устройство за запазване (задържане) на езика - $50 \%$; септум/ раковина + палатофарингопластика $59 \%$ - успех, докато хирургията на септум/раковина + палатофарингопластика + устройство за задържане на езика - общо 67\%. (Laryngoscope 1985).

Като самостоятелна хирургията на много нива (multi-level) е описана и представена за първи път през 1989 г. от P. D. Waite и сътрудници (J. Oral Matilla fac. Surg.). Те са комбинирали при OCA интервенции върху носа, мекото небце и езика с genioglossus - преместване напред и мандибуломаксиларна остеотомия с разместване. Riley и сътр. (Otolaryngolog Head Neck Surh) са изтъкнали през 1993 г. това лечебно понятие, което се базира на три-етажно-въвеждане на фаринкса според Fujita (Ear-Nose Throat S 1993 г.). След това вече са използвани многобройни комбинации от интервенции за разширяване на горния дихателен път. След средата на 60-те години на 20-ти век се доказа, че хирургията има твърди позиции в лечението на СОНД заедно със златния стандарт - на повишено налягане при отдишване по време на 
сън (СРАР и модификации) и заедно с оралните апликатори. Тук се числят преди всичко много ефективните трахеотомия, аденотонзилектомия в детска възраст и остеотомията с разместване в мандибуло-максиларната област.

Другите операции за отстраняване на местата на обструкция в горните дихателни пътища са доказали с времето, че са по-малко ефективни, но при много пациенти се прилагат като смислено допълнение в рамките на multi-level терапията.

B заключение едно изображение на G. B. Shaws or неговата книга „Лекарят на кръстопът“ от 1906 г., което показва оценката на значението на тонзилотомията и увулотомията от гледна точка на писателя, как тонзилотомията през годините на миналия век е имала нараствацо и все по-голямо значение. По отношение на отстраняването на увулата като общо лечително средство за (при) индикация на СОНД все пак още нищо не се е променило. Така Shaw описва няколко хирурзи, които отново и отново търсят нови източници:

\section{Литература:}

1. Levinus Lemnious: The touchstone of complexions. London 1581

2. Cline CL: The effects of intra-nasal obstruction on the general health. Medical and Surgical Reports 1892; 67: 259-260

3. Wells WA: Some nervous and mental manifestations occurring in connection with nasal disease. Am J Med Sci 1898; 116: 677-692 11

4. Rappai M, Collop N, Kemp S, deShazo R: The nose and sleep-disordered breathing. What we know and what we do not know. Chest 2003; 124:2309-2323

5. Verse T, Pirsig W: Impact of impaired breathing on sleep-disordered breathing. Sleep Breath 2003; 7: 63-76

6. Rombaux Ph, Liistro G, Hamoir M, Bertrand B, Aubert G, Verse T, Rodenstein D: Nasal obstruction and its impact on sleep-related breathing disorders. Rhinology 2005; 43 : 242-250

7. Kerr P, Millar T, Buckle P, Kryger M: The importance of nasal resistance in obstructiv sleep apnea syndrome. J Otolaryngol 1992; 21: 189195

8. McNicholas WT, Tarlo S, Cole P, et al: Obstructive apneas during sleep in patients with seasonal allergic rhinitis. Am Rev Respir Dis 1982; 126: $625-628$

9. Lavie P, Gertner R, Zomer J, Podoshin L: Breathing disorders in sleep associated with "microarousals' in patients with allergic rhinitis. Acta Otolaryngol 1981; 92: 529-533

10. Craig TJ, Mende C, Hughes K, Kakumanu S, Lehman EB, Chinchilli $\mathrm{V}$ : The effect of topical nasal fluticasone on objective sleep testing and the symptoms of rhinitis, sleep, and daytime somnolence in perennial allergic rhinitis. Allergy asthma Proc 2003; 24: 53-58

11. Hughes K, Glass C, Ripchinski M, Gurevich F, Weaver TE, Lehman E, Fisher LH, Craig TJ: Efficacy on the topical nasal steroid budesonide on improving sleep and daytime somnolence in patients with perennial allergic rhinitis. Allergy 2003; 58: 380-385

12. Brouillette RT, Manoukian JJ, Ducharme FM, et al:. Efficacy of fluticasone nasal spray for paediatric obstructive sleep apnea. J Pediatr 2001; 138: $838-844$

13. Kiely JL, Nolan P, McNicholas WT: Intranasal corticosteroid therapy for obstructive sleep apnea in patients with co-existent rhinitis. Thorax 2004: 59: 50-55

14. Petruson B: Increased nasal breathing decreases snoring and improves oxygen saturation during sleep apnea. Rhinology 1994; 32: 87-98

15. Afzelius LE, Elmquist D, Hougaard K, et al: Sleep apnea syndrome
„Сър Патрик: „Аз познавам вашия Cutler Walpole (сръчен оператор и лекар, лекувац рани с хлороформ) и нему подобните. Те са открили, че тялото на човека е изпълнено с остатъци от стари органи, които имат своето предназначение. Благодарение на хлороформа може да се изреже дузина от тях, без това да навреди на човека по някакъв начин, без да се държи сметка за болестта и златните парченца, които са доставяли удоволствие. Аз познавам добре от преди 15 години това качество. Бащата се грижеше за пациента - за 50 лири стерлинги да се ампутира върхът на мъжеца на небцето и гърлото да се обработва с четчица през цялата година ежедневно с разяждаща основа; струваше по 2 лири стерлинги дневно. Неговият шурей (зет, баджанак) изряза напълно сливиците за 200 .... (лири стерлинги), докато за двоен хонорар той трябваше да потърси (да се обърне) (към) „женските мъки“ (преведено от Зигфрид Трайбич).

-An alternative treatment to tracheotomy. Laryngoscope 1981; 91: 285 291

16. Nahmias JS, Karetzky MS: Treatment of the obstructive sleep apnea syndrome using a nasopharyngeal tube. Chest 1988; 94: 1142-1147

17. Masters IB, Chang AB, Harris M, O'Neil MC: Modified nasopharyngeal tube for upper airway obstruction. Arch Dis Child 1999; 80 186-18712

18. Woodhead CJ, Allen MB: Nasal surgery for snoring. Clin Otolaryngol 1994; 19: 41-44

19. Fairbanks DNF: Snoring: surgical vs nonsurgical management. Laryngoscope 1984; $94: 1188-1192$

20. Low WK: Can snoring relief after nasal septal surgery be predicted? Clin Otolaryngol 1994;19: 142-144

21. Illum P: Septoplasty and compensatory inferior turbinate hypertrophy long-term results after randomized turbinoplasty. Eur Arch Otorhinolaryngol 1997; Suppl 1: S89-S92

22. Heimer D, Scharf S, Liebermann A, et al: Sleep apnoea syndrome treated by repair of deviated nasal septum. Chest 1983; 84: 184-185

23. Simmons FB, Hill MW: Hypersomnia caused by upper airway obstruction. Ann Otol Rhinol Laryngol 1974; 83: 670-673

24. Dreher A, de la Chaux R, Grevers G, Kastenbauer E: Influence of nasal obstruction on sleep-associated breathing disorders [in German]. Laryngorhinootologie 1999;78:313-317

25. Simmons FB, Guilleminault C, Dement WC, et al: Surgical management of airway obstruction during sleep. Laryngoscope 1977; 87: 326338

26. Rubin AHE, Eliaschar I, Joachim Z, Alroy G, Lavie P: Effects of nasal surgery and tonsillectomy on sleep apnea. Bull Eur Physiopathol Respir 1983; 19: 612-615

27. Dayal VS, Phillipson EA: Nasal surgery in the management of sleep apnea. Ann Otol Rhinol Laryngol 1985; 94: 550-554

28. Caldarelli DD, Cartwright R, Lilie JK: Obstructive sleep apnea: variations in surgical management. Laryngoscope 1985; 95: 1070-1073

29. Aubert-Tulkens G, Hamoir M, van den Eeckhaut J, Rodenstein DO: Failure of tonsil and nose surgery in adults with long-standing severe sleep apnea syndrome. Arch Intern Med 1989: 149: 2118-2121

30. Sériès F, Pierre S St, Carrier G: Effects of surgical correction of nasal obstruction in the treatment of obstructive sleep apnea. Am Rev Respir Dis 1992; 146: 1261-1265 
31. Sériès F, Pierre S St, Carrier G: Surgical correction of nasal obstruction in the treatment of mild sleep apnoea: importance of cephalometry in predicting outcome. Thorax 1993; 48:360-363

32. Utley DS, Shin EJ, Clerk AA, Terris DJ: A cost-effective and rational surgical approach to 13 patients with snoring, upper airway resistance syndrome, or obstructive sleep apnea syndrome. Laryngoscope 1997; 107: 726-734

33. Verse T, Pirsig W, Kroker BA: Obstructive sleep apnea and nasal polyps. [in German] Laryngorhinootologie 1998; 77: 150-152

34. Friedman M, Tanyeri H, Lim JW, et al: Effect of improved nasal breathing on obstructive sleep apnea. Otolaryngol Head Neck Surg 2000; 122 : 71-74

35. Verse T, Maurer JT, Pirsig W: Effect of nasal surgery on sleep related breathing disorders. Laryngoscope 2002; 112: 64-68

36. Dagan Y: Rhinoplasty and sleep apnea syndrome. Somnologie $1997 ; 1$ (Suppl 2): 49

37. Lavie P, Zomer J, Eliaschar I, et al: Excessive daytime sleepiness and insomnia. Association with deviated nasal septum and nocturnal breathing disorders. Arch Otolaryngol 1982; 108: 373-377

38. Sher AE, Schechtman KB, Piccirillo JF: The efficiency of surgical modifications of the upper airway in adults with obstructive sleep apnea syndrome. Sleep 1996; 19: 156-177

39. Kim ST, Choi JH, Jeon HG, Kim DY, Chung YS: Polysomnographic effects of nasal surgery for snoring and obstructive sleep apnea. Acta Otolaryngol (Stockh) 2004; 124: 297-300

40. Busaba NY: Same-stage nasal and palatopharyngeal surgery for obstructive sleep apnea: is it safe? Otolaryngol Head Neck Surg 2002; 126 : 399-403

41. Kalan A, Kenyon GS, Seemungal TAR, Wedzicha A: Adverse effects of nasal continuous positive airway pressure therapy in sleep apnoea syndrome. J Laryngol Otol 1999; 888-892

42. Lojander J, Brander PE, Ämmälä K: Nasopharyngeal symptoms and nasal continuous positive airway pressure therapy in obstructive sleep apnoea syndrome. Acta Otolaryngol (Stockh) 1999; 119: 497-502

43. Verse T, Lehnhardt E, Pirsig W, Junge-Hülsing B, Kroker B: Welche Nebenwirkungen hat die nächtliche Überdruckbeatmung bei Schlafapnoikern im Kopf-Hals-Bereich. Eine retrospektive Analyse. Laryngorhinootologie 1999; 78: 491-496

44. Pépin JL, Leger P, Veale D, et al: Side effects of nasal continuous positive airway pressure in sleep apnea syndrome. Chest 1995; 107 : $375-381$
45. Rubinstein I: Nasal inflammation in patients with obstructive sleep apnea. Laryngoscope 1995; 105: 175-177

46. Hayes MJ, McGregor FB, Roberts DN, Schroter RC, Pride NB: Continuous nasal positive airway pressure with a mouth leak: effect on nasal mucosal blood flux and nasal geometry. Thorax 1995; 50: 1179-1182

47. Constantinidis J, Knöbber D, Steinhart H, Kuhn J, Iro H: Fine-structural investigations of the effect of the nCPAP mask application on the nasal mucosa. Acta Otolaryngol 2000; 120: 432-437

48. Powell NB, Zonato AI, Weaver EM, Li k, Riley RW, Guilleminault C: Radiofrequency treatment of turbinate hypertrophy in subjects using continuous airway pressure: a randomized, double-blind, placebo-controlled clinical pilot trial. Laryngoscope 2001; 1783-1790

49. Esteller E, Matino E, Segarra F, Sanz JJ, Adema JM, Estivill E: Efectos adversos derivados del tratamiento con nCPAP y su relacion con la nariz. Acta Otorhinolaringologica Espanola 2004; 55 : 17-22

50. Biermann E: Nasal CPAP therapy in obstructive sleep apnea syndrome: Does functional rhinosurgery improve compliance? [in German] Somnologie $2001 ; 5:$ 59-64

51. Cassisi NJ, Biller HF, Ogura JH: Changes in arterial oxygen tension and pulmonary mechanics with the use of posterior packing in epistaxis: A preliminary report. Laryngoscope 1971; 81: 1261-1266

52. Wetmore SJ, Scrima L, Hiller FC: Sleep apnea in epistaxis patients treated with nasal packs. Otolaryngol Head Neck Surg 1988; 98: 596599

53. Benumof JL: Obstructive sleep apnea in the adult obese patient: implications for airway management. J Clin Anesth 2001; 13: 144-156

54. Dorn M, Pirsig W, Verse T: Management of patients with severe obstructive sleep apnea following rhinosurgical interventions. A pilot study. [in German] HNO 2001; 49: 642-645

55. Hoffstein V, Mateika S, Metes A: Effect of nasal dilation on snoring and apneas during different stages of sleep. Sleep 1993; 16:360-365

56. Nakata S, Noda A, Yagi H, Yanagi E, Mimura T, Okuda T, Misawa H, Nakashima T: Nasal resistance for determinant factor of nasal surgery in CPAP failure patients with obstructive sleep apnea syndrome. Rhinology $2005 ; 44: 296-299$ 